\title{
Generation of Atmospheric Pressure Dielectric Barrier Discharge (DBD) using Water Electrode
}

\section{Roshna Manandhar, Deepak Prasad Subedi, Rajesh Prakash Guragain, and Rabin Baral}

Journal of Nepal Physical Society

Volume 7, No 3, 2021

(Special Issue: ANPA Conference, 2021)

ISSN: 2392-473X (Print), 2738-9537 (Online)

Editors:

Dr. Nabin Malakar (Editor in chief)

Worcester State University

Dr. Pashupati Dhakal

Thomas Jefferson National Accelerator Facility, USA

Dr. Arjun Dahal

University of South Alabama, USA

Dr. Chiranjivi Lamsal

SUNY Platsburgh, USA

Dr. Dilli Raj Paudyal

University of Regina, Canada

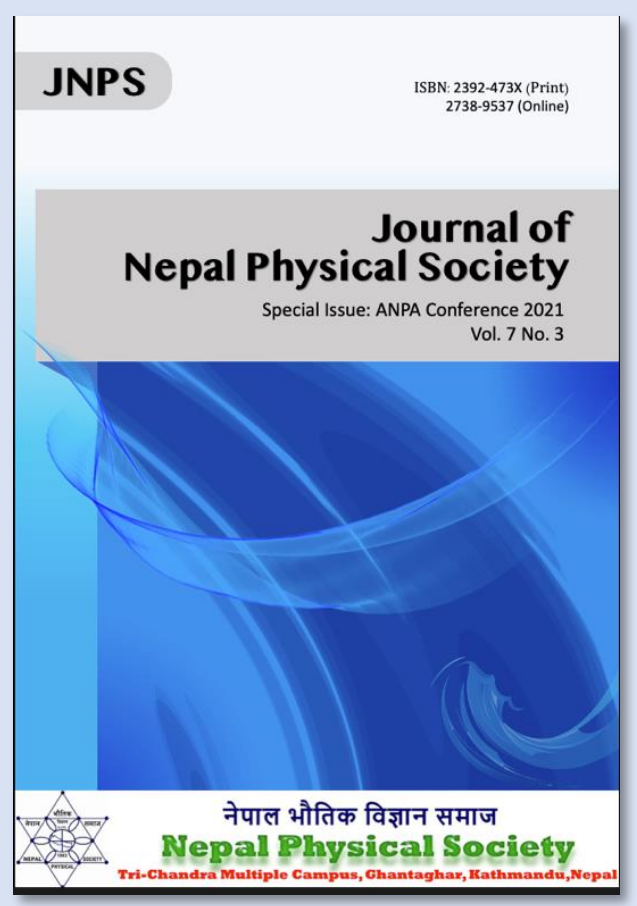

Managing Editor:

Dr. Binod Adhikari

St. Xavier's College, Kathmandu, Nepal

JNPS, 7 (3), 27-33 (2021)

DOI: http://doi.org/10.3126/jnphyssoc.v7i3.42187

Published by: Nepal Physical Society

P.O. Box: 2934

Tri-Chandra Campus

Kathmandu, Nepal

Email: npseditor@gmail.com 


\title{
GENERATION OF ATMOSPHERIC PRESSURE DIELECTRIC BARRIER DISCHARGE (DBD) USING WATER ELECTRODE
}

\author{
Roshna Manandhar ${ }^{12^{*}}$, Deepak Prasad Subedi ${ }^{2}$, Rajesh Prakash Guragain ${ }^{2}$, Rabin Baral ${ }^{1}$ \\ ${ }^{1}$ Department of Physics, St. Xavier's College, Tribhuvan University, Kathmandu, Nepal. \\ ${ }^{2}$ Department of Physics, School of Science, Kathmandu University, Kavre, Nepal \\ "Corresponding Author: roshnamdhr@gmail.com
}

\begin{abstract}
In this experiment, an atmospheric pressure dielectric barrier discharge (DBD) generated with a water electrode is investigated by means of optical measurements and imaging. The discharge was generated using a high voltage $(0-20 \mathrm{kV})$ power supply operating at $10-30 \mathrm{kHz}$ with water as one of the electrode and borosilicate glass as a dielectric barrier of $2.5 \mathrm{~mm}$ thickness. This paper reports the generation and characterization of atmospheric pressure plasma in nitrogen environment and its application in the surface modification of polyethylene terephthalate (PET). The generated plasma has been characterized by image analysis and optical emission spectroscopy. Our results showed that the distribution of micro-discharges depends significantly on the inter electrode gap and applied voltage. In order to characterize the discharge, electron temperature has been determined by using line intensity ratio method. The results showed that $\mathrm{T}_{\mathrm{e}}$ depends on applied voltage and pressure inside the chamber. The values of $\mathrm{T}_{\mathrm{e}}$ were found to be $1.40 \mathrm{eV}$ and $0.95 \mathrm{eV}$ applied at $1 \mathrm{kV}$ and $10 \mathrm{kV}$ voltage using $1 \%$ concentration. The discharge was produced at various conditions for the study of effectiveness of treatment on the surface property of Polyethylene terephthalate (PET). After the treatment of the sample in different treatment time: $10 \mathrm{~s}, 20 \mathrm{~s}, 40 \mathrm{~s}$, and $60 \mathrm{~s}$, the hydrophobic properties of sample changed to the hydrophilic. To investigate the effect of plasma treatment on Polyethylene terephthalate (PET) polymer contact angle was measured by using goniometer with water as a testing liquid. The surface properties of the untreated and plasma treated PET samples were characterized by contact angle measurement, and surface energy analysis. Before treatment the contact angle for untreated sample was $77.1^{\circ}$ and after treatment its contact angle becomes $38.7^{\circ}, 35.04^{\circ}, 33.6^{\circ}$ and $31.6^{\circ}$ respectively.
\end{abstract}

\section{Received: Aug 30, 2021; $\quad$ Revised: Dec 29, 2021; $\quad$ Accepted: Dec 31, 2021}

Keywords: Atmospheric pressure plasma; Electron temperature; Optical Emission Spectroscopy

\section{INTRODUCTION}

Nonthermal and low-temperature plasma have become a topic of interest to research. Development of various types of lower - pressure system and atmospheric pressure system have already been developed. Polymer surface treatment, deposition of thin films and cleaning of substrates requires low-pressure plasma sources. $[1,2]$.

Low - pressure plasma got more popularity due to its wider field of applications such as: polymer treatment, surface cleansing, pollution control, thin film deposition, biological sterilization, water purification and many more. It has also a great importance in manufacturing semi-conductor devices and in materials processing. $[3,4,5]$ The surface treatment of polymers to enhance their hydrophilicity is one of the major areas of application of atmospheric pressure plasma. This implementation is motivated due to much superiority over the conventional method of surface treatment. [6, 7].

Polymers are generally macromolecules formed by the repeated linking of a large number of small 
molecules [8]. Polymers which play a significant role as structural materials are generally utilized in industries $[9,10]$. Due to their superior performance, low cost, good breakage resistance, transparency, and low inflammability polymers are fascinating business articles. Their surface modification is mandatory due to its low hardness, low scratch resistance, and degradation by UV radiation $[11,12]$. With low surface energy, poor chemical reactivity, and a weak cohesion layer on the surface, it is vital to enhance the surface properties of polymers without changing the bulk properties [13, 14]. PET is an inert material and is widely accepted as a safe and recyclable plastic. Due to these reasons, it is widely used in beverage packaging, electronics, and biomedical industries. Similar to glass, it is hygienic and generally resistant to attack by bacteria and other microorganisms [15].

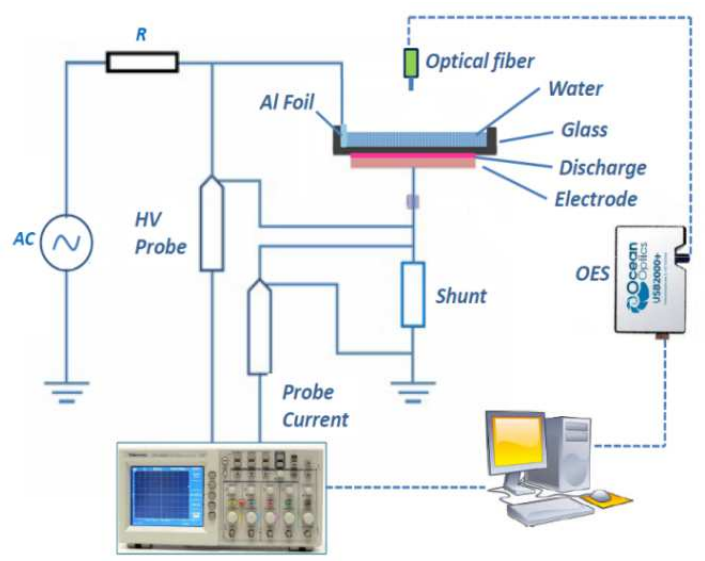

Figure 1: Schematic diagram of the experimental setup

DBD plasma with a liquid electrode in atmospheric air is scarce in scientific literature and a topic of an ongoing investigation. This is mainly due to plasmas in liquids are more tangled than their counterparts in the gas phase. They are in a highly non-equilibrium state and are mostly generated in both gas and liquid state. In particular species and charge transfer mechanisms at the plasma liquid interface and the intensive evaporation make these discharges a lot more complex. Discharges in and in contact with liquids produce intense UV radiation, shock waves, and several reactive chemical species $(\mathrm{OH}$, atomic oxygen, hydrogen peroxide, etc ) As a result plasma is in or in contact with liquids suitable for a large variety of potential applications. It becomes very effective in the treatment of many biological and chemical matters. This makes liquid plasmas particularly suitable for water remediation and polymer surface activation. That's why this kind of plasma has been studied extensively in the last two decades. Liquids were already introduced in the plasma field in the 20th century, so the field is not as new as often thought [16].

\section{METHODS}

The reactor was designed and fabricated at the Kathmandu University Plasma Physics laboratory. The experimental setup consists of a DBD system with water as one of the electrode and borosilicate glass as a dielectric barrier of $2.5 \mathrm{~mm}$ thickness. The electrodes are connected to a high-voltage $(0-20 \mathrm{kV})$ operating at (10-30) $\mathrm{kHz}$ frequency. The distance between two electrodes is fixed. Plasma was produced at atmospheric pressure in air. The schematic diagram of the experimental setup and the nature of the discharge are shown in Figure 1 and Figure 2.

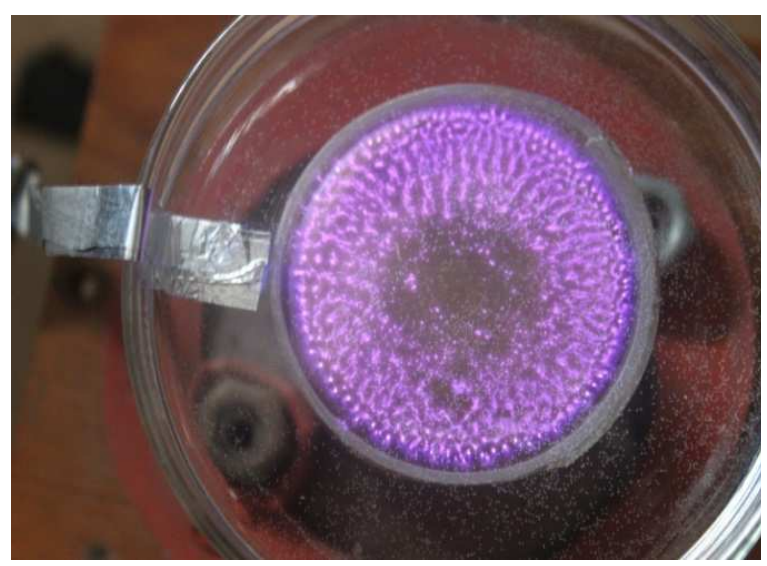

Figure 2 : Image of Discharge

Frequency is maintained at $27 \mathrm{kHz}$. . The discharge thus obtained was investigated by image analysis and optical emission spectroscopy. The optical characterization of the discharge has been done using the line intensity ratio method with the help of an optical emission spectrometer (USB 2000+, Ocean Optics). The contact angle of the untreated and plasma treated PET samples is measured using the Rame Hart contact angle goniometer (Model 200). Before the treatment, the samples of PET of dimension $(50 \mathrm{~mm} \times$ $15 \mathrm{~mm} \times 0.05 \mathrm{~mm}$ ) were taken.

The samples were provided by Good fellow, U.K. Before treatment, polymer samples were washed in 
isopropyl alcohol in order to remove organic contaminants from the surface of the specimens. The samples were then ultrasonically cleaned in distilled water for 10 minutes and dried at room temperature. The contact angle measurement was done at five different locations of the same samples and the average value of the contact angle thus obtained was used for the surface energy calculations [17].

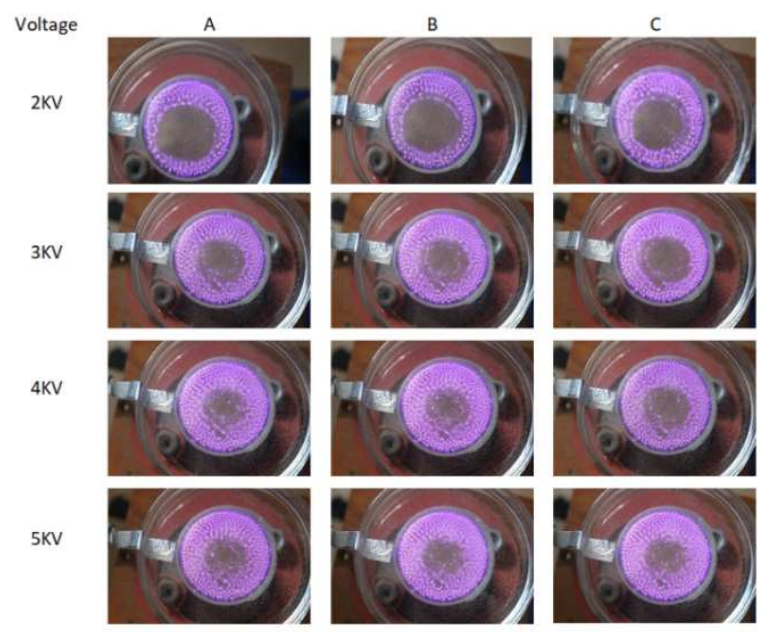

Figure 3: Three images of discharge $\mathrm{A}, \mathrm{B}$ and $\mathrm{C}$ at $27 \mathrm{kHz}$ by applying voltage of $2 \mathrm{kV}, 3 \mathrm{kV}, 4 \mathrm{kV}$ and $5 \mathrm{kV}$ respectively.

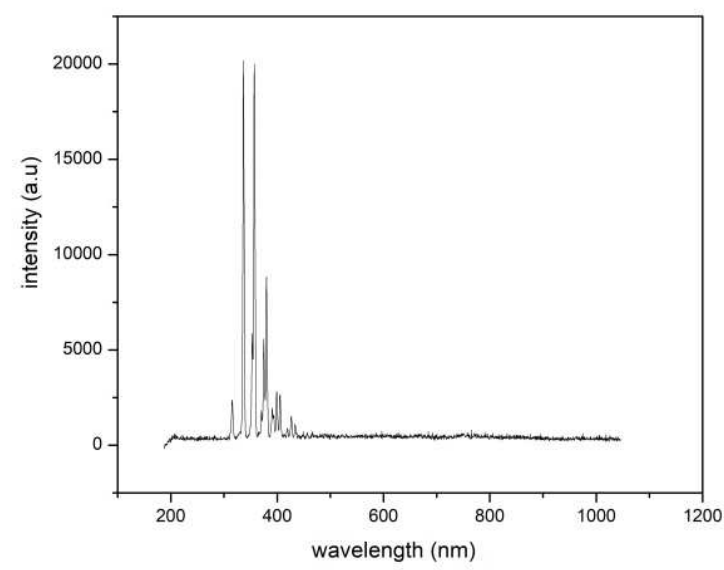

Figure 4: Optical Emission Spectroscopy of Atmospheric Pressure Dielectric Barrier Discharge.

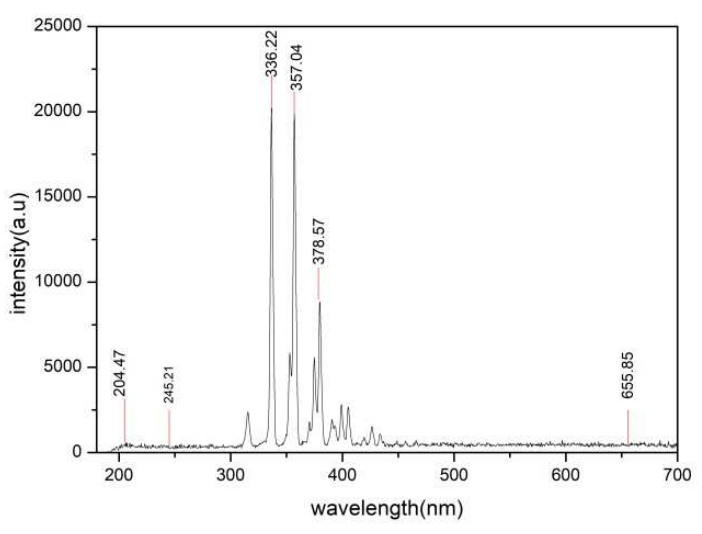

(a)

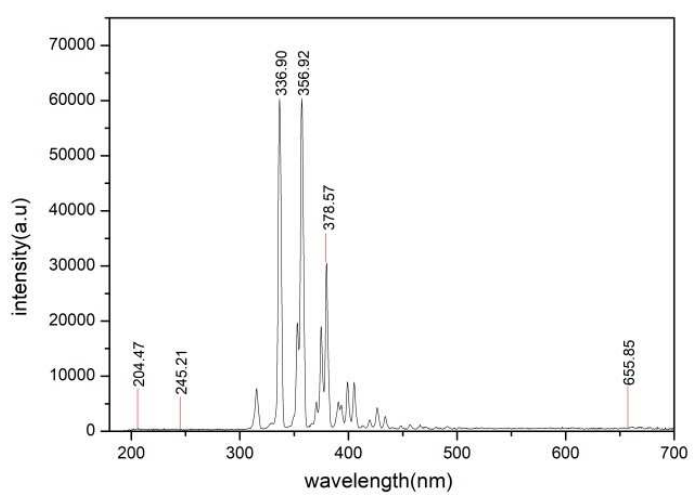

(b)

Figure 5: Spectra of APDBD in the range of $180 \mathrm{~nm}$ to $700 \mathrm{~nm}$ a) at $1 \mathrm{kV}$ having $1 \% \mathrm{HNO}_{3}$ solution; (b) at $10 \mathrm{kV}$ having $1 \% \mathrm{HNO}_{3}$ solution.

\section{RESULTS AND DISCUSSION}

I. Image analysis: The discharge thus obtained was investigated by image analysis by using high resolution digital camera. Our results showed that the distribution of micro - discharges depends significantly on the inter electrode gap and applied voltage. Images of discharge at $27 \mathrm{kHz}$ using water electrode is shown in figure 3 .

\section{Optical Characterization of the Discharge:}

Figure 4 shows the spectra of the discharge and their corresponding intensities and wavelength using 


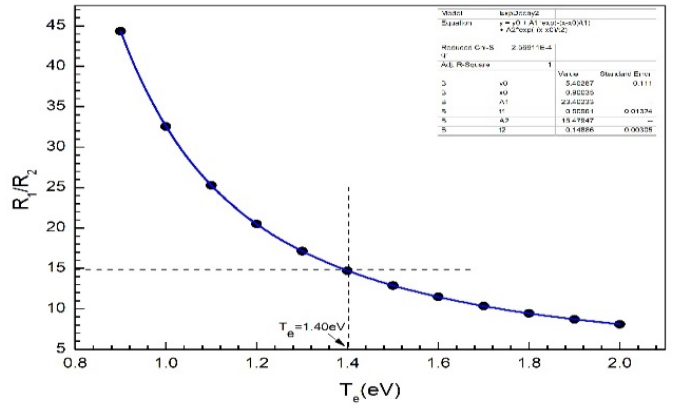

(a)

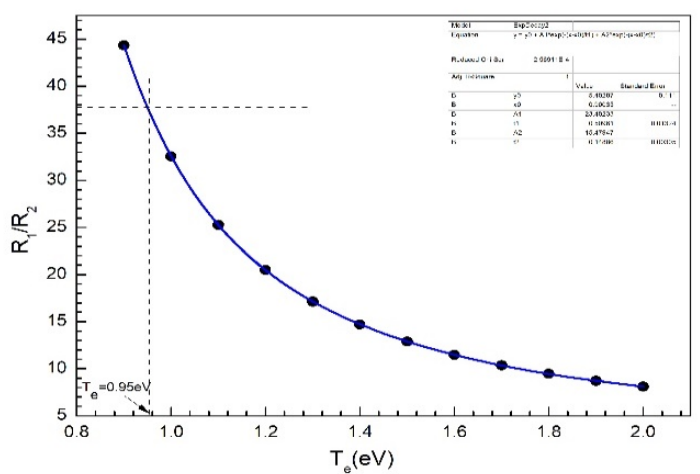

(b)

Figure 6: Plot of $R_{1} / R_{2}$ as a function of $T_{e}$ applied voltage a) $1 \mathrm{kV}$ and b) $10 \mathrm{kV}$ having $1 \% \mathrm{HNO}_{3}$ solution.

atmospheric air. Figure 5 shows the spectra of APDBD in the range of $180 \mathrm{~nm}$ to $700 \mathrm{~nm}$ at $1 \mathrm{kV}$ and $10 \mathrm{kV}$ applied voltage using $1 \% \mathrm{HNO}_{3}$ solution. The optical characterization of the discharge was carried out by using the line intensity ratio method. In this method, four suitable lines (two for NII and two for NIII) are chosen and electron temperatures is estimated using the lines intensity ratio method obtained from the discharge. The working formula used to calculate the electron temperature is as follows

$\frac{R_{1}}{R_{2}}=\frac{\frac{I_{1}}{I_{2}}}{\frac{I_{3}}{I_{4}}}=\left(\frac{A_{p q}}{A_{r s}}\right)\left(\frac{g_{p}}{g_{r}}\right)\left(\frac{\lambda_{r s}}{\lambda_{p q}}\right)\left(\frac{A_{u v}}{A_{x y}}\right)$

$$
\left(\frac{g_{u}}{g_{x}}\right)\left(\frac{\lambda_{x y}}{\lambda_{u v}}\right) \operatorname{Exp}\left[-\frac{E_{p}-E_{r}-E_{x}+E_{u}}{K T_{e}}\right]
$$

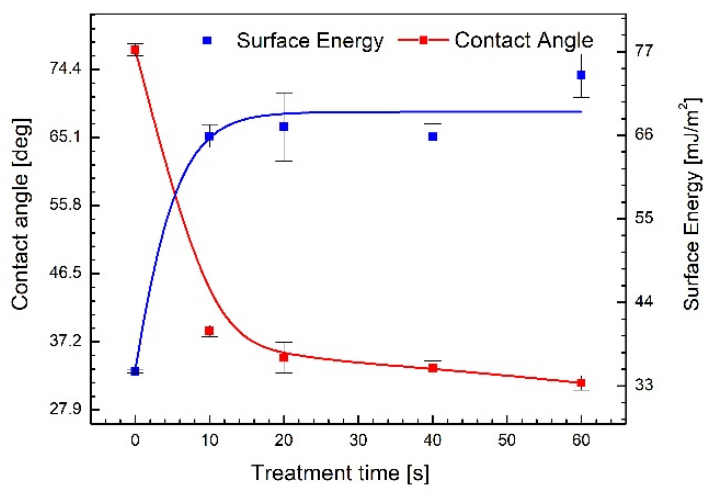

Figure 7: Contact angle and surface energy as a function of the treatment time in the discharge.

Here, in Equation (1), $\mathrm{R}$ is the ratio of the intensity of two lines, $\mathrm{I}$ is the intensity of the spectral line, $\mathrm{A}_{\mathrm{ij}}$ is the transition probability of the transition $i \rightarrow j, g_{i}$ is the statistical weight of the upper level, $\lambda$ is the wavelength of the line radiation, $E_{i}$ is the energy of the upper level, $\mathrm{KB}$ is the Boltzmann constant, and $\mathrm{T}_{\mathrm{e}}$ is the electron temperature. The values of $\lambda$ and $I$ are obtained from the observation, and the values of $\mathrm{A}_{\mathrm{ji}}, \mathrm{g}_{\mathrm{i}}$, and $\mathrm{E}_{\mathrm{i}}$ are obtained from the National Institute of Standards and Technology (NIST) Atomic Spectra Database.The corresponding values of the transition probability, statistical weight, and energy levels for the Nitrogen II and Nitrogen III lines were obtained through the NIST database [18]. Table 1 shows the corresponding value of the ratio of the intensity of the spectral lines $\left(R_{1} / R_{2}\right)$ with change in electron temperature $\left(\mathrm{T}_{\mathrm{e}}\right)$.

Table 1: Values of $R_{1} / R_{2}$ for different $T_{e}$

\begin{tabular}{l|l}
\hline $\begin{array}{l}\text { Electron temperature } \\
\mathrm{T}_{\mathrm{e}}(\mathrm{eV})\end{array}$ & Intensity ratio $\mathrm{R}_{1} / \mathrm{R}_{2}$ \\
\hline 0.9 & 44.34 \\
\hline 1.0 & 32.56 \\
\hline $1 . .1$ & 25.28 \\
\hline 1.2 & 20.48 \\
\hline 1.3 & 17.14 \\
\hline 1.4 & 14.71 \\
\hline 1.5 & 12.88 \\
\hline 1.6 & 11.47 \\
\hline 1.7 & 10.36 \\
\hline 1.8 & 9.46 \\
\hline 1.9 & 8.72 \\
\hline 2.0 & 8.10 \\
\hline
\end{tabular}


From Figure 6, the electron temperature $\left(\mathrm{T}_{\mathrm{e}}\right)$ was found to be $1.40 \mathrm{eV}$ for applied voltage $1 \mathrm{kV}$ and $0.95 \mathrm{eV}$ for applied voltage $10 \mathrm{kV}$ using $1 \% \mathrm{HNO}_{3}$ solution respectively.

\section{Surface Modification of Polyethylene Terephthalate (PET)}

\section{Contact Angle and Surface Energy Measurements}

For an ideal, smooth, and homogeneous surface, the water contact angle and surface free energy are measured at the equilibrium according to Young's equation and Fowke's equation respectively [19] [20].

$$
\operatorname{Cos} \theta=\frac{\gamma_{s v}-\gamma_{s l}}{\gamma_{l v}}
$$

where $\gamma_{\mathrm{sv}}$ is the surface free energy of the solid substrate, $\gamma_{\mathrm{sl}}$ is the interfacial tension between the solid and the liquid, and $\gamma_{\mathrm{lv}}$ is the surface tension of the liquid. For two liquids $i$ and $j$,

$$
\begin{aligned}
& \gamma_{l i}\left(1+\operatorname{Cos} \theta_{i}\right)=2\left[\gamma_{l i}^{d} \gamma_{s}^{d}\right]^{\frac{1}{2}}+2\left[\gamma_{l i}^{p} \gamma_{s}^{p}\right]^{1 / 2} \\
& \gamma_{l j}\left(1+\operatorname{Cos} \theta_{j}\right)=2\left[\gamma_{l j}^{d} \gamma_{s}^{d}\right]^{\frac{1}{2}}+2\left[\gamma_{l j}^{p} \gamma_{s}^{p}\right]^{1 / 2}
\end{aligned}
$$

Substituting the known values of the surface tension and its polar and dispersion components of the test liquids, components of surface free energy of the solid $\gamma_{s}^{p}$ and $\gamma_{s}^{d}$ can be determined by solving Equations (3) and (4). The sum of these two quantities eventually gives the total surface energy of the solid.

The treatment of the sample was performed for various exposure times $(0-60$ seconds $)$. The effect of this parameter on hydrophilicity was scrutinized by contact angle measurement with water as a testing liquid on the surface. It is seen that a rapid decrease in the static water contact angle takes place with the treatment time up to 20 seconds which shows an increase in wettability in the surface induced by APDBD treatment. Initially, the contact angle of the untreated PET for water was $77.1^{\circ}$, but after plasma treatment, the contact angle was effectively reduced to $35.04^{\circ}$ and became almost constant after 20 seconds of treatment time as shown in Figure 7. Images of water drops on PET polymer (untreated and treated) are shown in figure 8 . The reduction in contact angle might be due to the change in the surface roughness. [21]

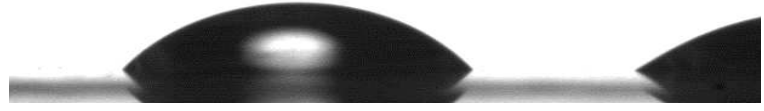

(a)
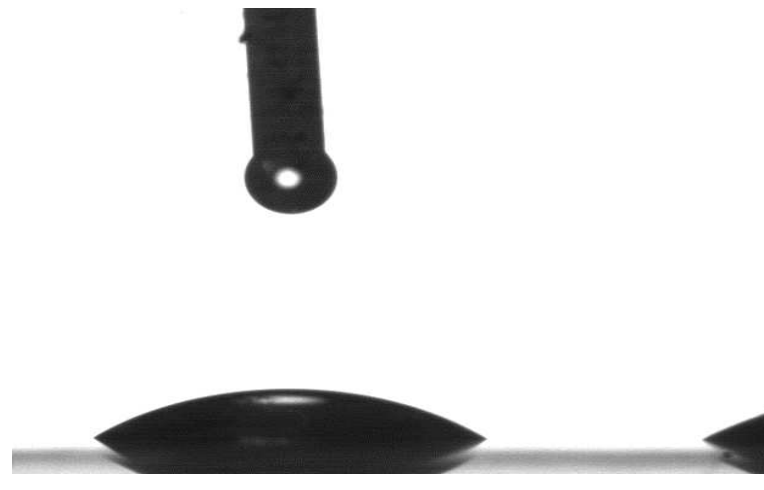

(b)

Figure 8: Images of water drops on PET polymer (a) Untreated (b) Treated

The variation of surface free energy and its various polar and dispersive components with treatment time for PET polymer is shown in Figure 9.

As seen in Figure 9, the surface energy of the untreated PET was found to be $34.9 \mathrm{~mJ} / \mathrm{m}^{2}$. It is seen that the surface energy significantly increases for a few second of treatment time, becomes maximum to about $73.9 \mathrm{~mJ} / \mathrm{m}^{2}$ after 20 seconds. Similar trend is also observed for the polar component and it is mainly due to the incorporation of the polar species such as carbonyl $(\mathrm{C}=\mathrm{O})$, hydroxyl $(-\mathrm{OH})$ and carboxyl $(-\mathrm{COOH})$ groups on the treated PET surface. The dispersive component decreases initially and remains almost constant which attributes to more physical change than chemical change. 
This component does not have any contribution to increase the wettability of the PET surface [17].

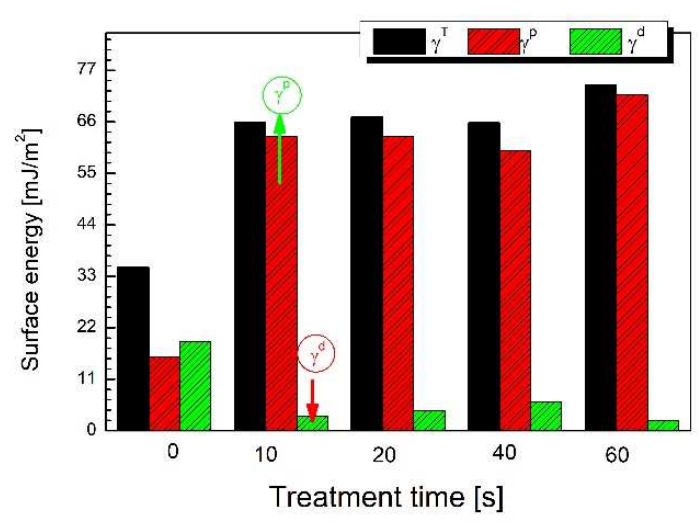

Figure 9: Variation of surface free energy with treatment time for PET samples.

\section{CONCLUSIONS}

The atmospheric-pressure plasma has been produced and characterized by image analysis and optical methods. DBD with a water electrode system facilitates the direct observation of the front view of the discharge which makes it possible to investigate the uniformity of the micro-discharges over the electrode surface. Our results showed that the distribution of micro discharges depends significantly on the inter electrode gap and applied voltage. Here the number of micro discharges increases with the increase in applied voltage.

Electron temperature $\left(\mathrm{T}_{\mathrm{e}}\right)$ were found to be $1.40 \mathrm{eV}$ and $0.95 \mathrm{eV}$ applied at $1 \mathrm{kVand} 10 \mathrm{kV}$ voltage using $1 \%$ concentration, respectively, using the line intensity ratio method. In general, electron temperature $T_{e}$ increases with increase applied voltage. But in this study, we observe that the electron temperature decreases slightly with an increase in the applied voltage. There is no any significant change in this experiment. Although this result is unlikely, it has good agreement with the results reported by Validity of electron Temperature, Measurement by Using Boltzmann Plot Method in
Radio Frequency Inductive Discharge in the Atmospheric Pressure Range.

Treatment of PET using the atmospheric-pressure plasma resulted in an improvement in hydrophilicity. It is mainly due to the increase in the polar component of the surface free energy after plasma treatment which indicates the formation of polar functional groups on the surface. The improvement of the wettability of PET strongly depends on the treatment time. Results showed that there is a significant reduction in the water contact angle on the polymer surface after plasma treatment with a consequent increase in its surface free energy.

\section{AUTHOR CONTRIBUTIONS}

Deepak Prasad Subedi presented the idea for the paper. Roshna Manandhar carried out the methodology, data processing, experimental methodology and draft preparation; Rajesh Prakash Guragain helped in the analytical methods and experimental set up. Rabin Baral provided computational resources and carried out manuscript editing tasks. Finally, Deepak Prasad Subedi contributed to the final version of the manuscript.

\section{EDITOR'S NOTE}

This manuscript was submitted to the Association of Nepali Physicists in America (ANPA) Conference 2021 for publication in the special issue of Journal of Nepal Physical Society.

\section{REFERENCES}

[1] Konuma, M., Film deposition by plasma techniques, Springer Series on Atomic, Optical, and Plasma Physics, Springer-Berlin, 1992, Volume 10, (pp. 149-184).

[2] Roth, J. R., Industrial Plasma Engineering: Application to non-thermal plasma processing, IOP, 2001, Volume 2 Bristol and Philadelphia

[3] Ogawa, R.; Ogawa, H. ; Oki, A. ; Hashioka, S. and Horiike, Y. ; Thin Solid Films, Elsevier, 2007, volume 515, (pp. 5167-5171)

[4] Buddy, D.;Ratner., Surface modification of polymers: chemical, biological and surface analytical challenges. Elsevier, 1995, volume 10,(pp.797-804)

[5] Vetter, J.; Barbezat,G.;Crummenauer, J.; and Avissar, J.; Surface and Coatings Technology, Elsevier,2005, volume 200, (pp. 1962-1968)

[6] Vijayalakshmi, K.A.; Mekala, M.; Yoganand, C.P.; and Navaneetha Pandiyaraj, K. Studies on modification of 
surface properties in polycarbonate (PC) film induced by DC glow discharge plasma. IJPS, 2011, volume 2011

[7] Baniya, H.B.; Shrestha, R.; Shrestha, A. Surface modification of polycarbonate by atmospheric pressure argon/air plasma jet. JESTEC, 2014, volume 10, (pp.1316).

[8] Friedrich, K. Polymer composites for tribological applications. Advanced Industrial and Engineering Polymer Research, 2018, volume 1, (pp. 3-39).

[9] Hegemann, D.; Brunner, H.; and Oehr, C. Plasma treatment of polymers for surface and adhesion improvement. Nucl Instrum Methods Phys Res B. 2003, volume 208, (pp. 281-286).

[10] Shrestha, R.T; An experimental study of atmospheric pressure plasma jet and its applications, $\mathrm{PhD}$ thesis, Department of Natural Sciences, School of Science, Kathmandu University, Nepal, 2016.

[11] Sarani, A.; Nikiforov, Y.; Geyter, N.de.; Morent, R.; and Leys, C. Surface modification of polypropylene with an atmospheric pressure plasma jet sustained in argon and an argon/-water vapour mixture. Appl. Surf. Sci. 2011, volume 257, (pp. 8737-8741)

[12] Subedi, D.P.; Madhup, D.K.; Adhikari, K.; and Joshi, U.M. Plasma treatment at low pressure for the enhancement of wettability of polycarbonate. Indian J. Pure Appl. Phys. 2008, volume 46, (pp. 540-544).

[13] Guragain, R.; Gautam, S.; Shrestha, R.; and Subedi, D.P. Surface modification of polycarbonate by treatment with $50 \mathrm{~Hz}$ dielectric barrier discharge at near atmospheric pressure. Int. J. Sci. Res. (IJSR) 2016, volume 5, (pp. 1468-1470) .

[14] Baniya, H.B.; Shrestha, S.; and Subedi, D.P. Effect of floating electrode on the length of the capacitively coupled atmospheric pressure plasma jet. Int. J. Eng. Res. 2016, volume 4, (pp. 163-167).

[15] Shah, A.A.; Hasan, F.; Hameed, A.; and Ahmed, S. Biological degradation of plastics: a comprehensive review. Biotechnol. Adv. 2008, volume 26, (pp. 246265).

[16] Bruggeman, P.; and Leys, C. Non-thermal plasmas in and in contact with liquids. J. Phys. D Appl. Phys. 2009, volume 42, (pp. 053001)

[17] Baniya, H.B.; Shrestha, R.; Guragain, R.P.; Kshetri, M.B.; Pandey, B.P.; and Subedi, D.P. Generation and characterization of an atmospheric-pressure plasma jet (APPJ) and its application in the surface modification of polyethylene terephthalate. Int. J. Polym. Sci. 2020 , volume 2020.

[18] Kramida, A.; Ralchenko, Y.; Reader, J.; and NIST ASD Team, "NIST Atomic Spectra Database," 2018, March 2019, https://physics.nist.gov/asd

[19] Yuan, Y.; and Lee, T.R. Contact angle and wetting properties. Surf. Sci. 2013 (pp. 3- 34).
[20] Shrestha, R.; and Subedi, D.P. Experimental Study of an Atmospheric Pressure Dielectric Barrier Discharge and PET Surface Modification. Int J Eng Res Appl.2015, volume 5, (pp 41-45).

[21] Mui, T.S.M.; Mota, R.P.; Quade, A.; de Oliveira Hein, L.R.; and Kostov, K.G. Uniform surface modification of polyethylene terephthalate (PET) by atmospheric pressure plasma jet with a horn-like nozzle. Surf. Coat. Technol. 2018, volume 352, (pp 338-347). 